\title{
Dermabacter hominis
}

National Cancer Institute

\section{Source}

National Cancer Institute. Dermabacter hominis. NCI Thesaurus. Code C86335.

A species of aerobic, Gram positive, rod and cocci shaped bacterium assigned to the phylum Actinobacteria. This species is catalase positive, ferments glucose and variably ferments xylose and does not reduce nitrate. D. hominis is an opportunistic pathogen in immunocompromised individuals. 